\title{
Outcomes of photorefractive keratectomy in patients with atypical topography
}

\author{
Hossein Movahedan ${ }^{1}$, Ehsan Namvar ${ }^{2}$, Mohsen Farvardin ${ }^{3}$
}

\begin{abstract}
${ }^{1}$ M.D., Associate Professor of Ophthalmology, Poostchi Ophthalmology Research Center, Shiraz University of Medical Sciences, Shiraz, Iran

${ }^{2}$ M.D., Resident of Ophthalmology, Ophtalmology Department, Shiraz University of Medical Sciences, Shiraz, Iran

${ }^{3}$ Professor of ophthalmology, Poostchi Ophthalmology Research Center, Shiraz University of Medical Sciences, Shiraz, Iran
\end{abstract}

\section{Type of article: Original}

\begin{abstract}
Background: Photorefractive keratectomy (PRK) is at risk of serious complications such as corneal ectasia, which can reduce corrected distance visual acuity. The rate of complications of PRK is higher in patients with atypical topography.

Objective: To determine the outcomes of photorefractive keratectomy in patients with atypical topography.

Methods: This cross-sectional study was done in 2015 in Shiraz in Iran. We included 85 eyes in this study. The samples were selected using a simple random sampling method. All patients were under evaluation for uncorrected distance visual acuity, corrected distance visual acuity, manifest refraction, corneal topography, central corneal thickness using pentacam, slit-lamp microscopy, and detailed fondus evaluation. The postoperative examination was done 1-7 years after surgery. Data were analyzed using IBM SPSS 21.0 version. To analyze the data, descriptive statistics (frequency, percentage, mean, and standard deviation), chi-square, and independent samples t-test were used.

Results: We studied 85 eyes. Among the patients, 23 (27.1\%) were male and 62 (72.9\%) were female. Mean age of the participants was $28.25 \pm 5.55$ years. Mean postoperative refraction was $-0.37 \pm 0.55$ diopters. Keratoconus or corneal ectasia was not reported in any patient in this study. There was no statistically significant difference between SI index before and after operation $(\mathrm{p}=0.736)$. Mean preoperative refraction was $-3.84 \pm 1.46$ diopters in males and $-4.20 \pm 1.96$ diopters in females; thus there was not statistically significant difference $(p=0.435)$.

Conclusion: PRK is a safe and efficient photorefractive surgery and is associated with low complication rate in patients with atypical topography.
\end{abstract}

Keywords: Photorefractive keratectomy; Atypical topography; Keratoconus

\section{Introduction}

\subsection{Background and statement of problem}

Photorefractive keratectomy (PRK) is one of the most common refractive surgeries for correction of refractive errors using laser (1-3). This type of surgery may be a precipitating factor for serious complications in high-risk patients such as those with corneal ectasia, which can reduce corrected distance visual acuity (4-6). The rate of complications of PRK in eyes with normal topography is low. One study on 3000 eyes reported a rate of less than $1 \%$ for decrease in best corrected visual acuity after one-year follow-up (7). Another study reported no evidence of ectasia after 18 years' follow-up after PRK (8). The rate of complications of PRK is higher in patients with atypical topography (6, 9, 10). For example, higher rates of complications are reported in eyes with inferior topographic steepening and posterior cornea float. However, some studies have shown that PRK can be done safely in eyes with abnormal topography (2). Some topographic indexes such as I-S index, anterior elevation, posterior elevation, and corneal thinning are shown to be helpful in estimation of the likelihood of the complications $(7,11,12)$. Therefore, these

\section{Corresponding author:}

Dr. Ehsan Namvar, Ophtalmology Department, Shiraz University of Medical Sciences, Shiraz, Iran.

Tel: +98.9177134116, Email: namvar.e@gmail.com

Received: May 12, 2016, Accepted: August 30, 2016, Published: November 2017

iThenticate screening: August 27, 2016, English editing: October 19, 2016, Quality control: August 17, 2017

(C) 2017 The Authors. This is an open access article under the terms of the Creative Commons Attribution-NonCommercialNoDerivs License, which permits use and distribution in any medium, provided the original work is properly cited, the use is non-commercial and no modifications or adaptations are made. 
indexes are used to determine high-risk eyes for complications after PRK. It is shown that preoperative abnormalities of eye topography, including inferior steepening and keratoconus, can predict the postoperative corneal stability curvature, especially in young patients (13-15). However, some researchers have reported similar outcomes after one-year follow-up in patients with abnormalities in topography in comparison with patients with normal topography (16). However, the results of these studies are not conclusive.

\subsection{Objectives}

The general objective of the study was to determine the outcomes of photorefractive keratectomy in patients with atypical topography. The specific objectives of the study were as follows:

1) To compare SI index before and after PRK in patients with atypical topography

2) To determine mean postoperative refraction after PRK in patients with atypical topography

3) To determine the prevalence of corneal ectasia after PRK in patients with atypical topography

4) To compare the topographic indexes after PRK in patients with atypical topography according to sex

\section{Material and Methods}

\subsection{Study design and setting}

This cross-sectional study was done in 2015 in Shiraz University of Medical Sciences.

\subsection{Sampling and sample size calculation}

We included 85 eyes of 45 patients in this study using the following formula for sample size calculation:

$n=\left(\mathrm{Z}_{1-\alpha / 2}+\mathrm{Z}_{1-\beta}\right)^{2}\left(\mathrm{~s}_{1}{ }^{2}+\mathrm{s}_{2}{ }^{2}\right) / \mathrm{d}^{2}$. The samples were selected using the simple random sampling method. We have included the cases with atypical topography mainly inferior steepening by reviewing the charts of the patients.

\subsection{Inclusion and exclusion criteria}

The inclusion criterion was patients with topographic asymmetric inferior corneal steepening in at least two images. The exclusion criteria were the following underlying pathologies: belepharitis, contact lens wearer, technician error, and tear problem

\subsection{Measurement tools}

Preoperative evaluation included uncorrected distance visual acuity (UCVA), best corrected distance visual acuity (BCVA), manifest refraction, cyclorefraction, corneal topography, central corneal thickness using pentacam, slitlamp microscopy, and detailed fundus evaluation. The postoperative evaluation was done by calling the patients for outcome measurements, including the UCVA, BCVA, topographic, and tomographic data. The postoperative examination was done 1 to 7 years after surgery from 2008 to 2015 . We considered pachymetery $<500 \mu \mathrm{m}$, posterior elevation $>16 \mu \mathrm{m}$, anterior elevation $>8 \mu \mathrm{m}$, skew radial axis $>21$ degree, and keratometery $>47.2 \mu \mathrm{m}$ as atypical topographic indices.

\subsection{Statistical analysis}

Data were analyzed using IBM SPSS 21.0 version. To analyze the data, descriptive statistics (frequency, percentage, mean, and standard deviation), chi-square, and independent samples t-test were used. A $p$-value less than 0.05 was assumed to be significant.

\section{Results}

\subsection{Demographic information}

We studied 85 eyes in this study. Among the patients, 23 (27.1\%) were male and 62 (72.9\%) were female. Mean age of participants was $28.25 \pm 5.55$ years. Best corrected visual acuity of all patients was $20 / 20$. Minimum preoperative refraction was -1.00 diopters and maximum was -8.5 diopters (mean was $-4.10 \pm 1.84$ diopters). Mean duration between operation and assessment of the patients was $37.08 \pm 17.619$ months.

\subsection{Comparison of study parameters before and after operation}

Mean pre-SI index was $0.878 \pm 0.456$ diopters and mean post-SI index was $0.902 \pm 0.504$ diopters. There was no statistically significant difference between SI index before and after operation $(\mathrm{p}=0.736)$. There was no statistically significant difference between SI index before and after operation between different age groups (Table 1). 
http://www.ephysician.ir

Table 1. Comparison of study parameters before and after operation

\begin{tabular}{|l|l|l|l|}
\hline Topography Indexes & Preoperative & Postoperative & p-value \\
\hline Keratometery max (diopters) & $45.139 \pm 1.7196$ & $43.915 \pm 1.8002$ & $<0.001$ \\
\hline Thinnest $(\mu \mathrm{m})$ & $523.99 \pm 37.429$ & $449.84 \pm 30.764$ & $<0.001$ \\
\hline Anterior elevation $(\mu \mathrm{m})$ & $5.35 \pm 2.802$ & $8.06 \pm 4.263$ & $<0.001$ \\
\hline Posterior elevation $(\mu \mathrm{m})$ & $10.95 \pm 4.935$ & $11.99 \pm 4.651$ & 0.010 \\
\hline SI index (diopters) & $0.878 \pm 0.456$ & $0.902 \pm 0.504$ & $<0.001$ \\
\hline
\end{tabular}

\subsection{Preoperative study parameters}

Mean preoperative refraction was $-3.84 \pm 1.46$ diopters in males and $-4.20 \pm 1.96$ diopters in females; thus there was no statistically significant difference $(\mathrm{p}=0.435)$.

\subsection{Postoperative topography}

In Tables 2, 3, we have summarized the results of preoperative and postoperative topography in study participants. As shown in this table, abnormal post-operation abnormal elevation was the most common abnormality of topography after surgery. Mean postoperative refraction was $-0.37 \pm 0.55$ diopters. Corneal ectasia was not reported in any patient in this study. Mean postoperative refraction was $-0.23 \pm 0.45$ diopters in males and $-0.42 \pm 0.57$ diopters in females; thus there was no statistically significant difference $(\mathrm{p}=0.168)$.

\subsection{Preoperative and postoperative study parameters according to sex}

There was no statistically significant difference between males and females in study parameters before and after operation. Preoperative SI index was higher in females in comparison with males, but postoperative SI index was not different between males and females.

Table 2. Results of preoperative topography in study participants

\begin{tabular}{|l|l|l|}
\hline Index & Normal & Abnormal \\
\hline Keratometery max before operation & $80(94.1 \%)$ & $5(5.9 \%)$ \\
\hline Low pachymetery before operation & $64(75.3 \%)$ & $21(24.7 \%)$ \\
\hline Anterior elevation before operation & $72(84.7 \%)$ & $13(15.3 \%)$ \\
\hline Posterior elevation before operation & $72(84.7 \%)$ & $13(15.3 \%)$ \\
\hline Skewed radial axis before operation & $82(96.5 \%)$ & $3(3.5 \%)$ \\
\hline
\end{tabular}

Table 3. Results of postoperative topography in study participants

\begin{tabular}{|l|l|l|}
\hline Index & Normal & Abnormal \\
\hline Sum of thinnest point and ablation thickness after operation & $67(78.8 \%)$ & $18(21.2 \%)$ \\
\hline Posterior elevation after operation & $73(85.9 \%)$ & $12(14.1 \%)$ \\
\hline Skewed radial axis after operation & $67(78.8 \%)$ & $18(21.2 \%)$ \\
\hline
\end{tabular}

\section{Discussion}

In this study, we have reported on the high efficacy and safety of PRK in patients with atypical topography. Similar studies have shown the efficacy and safety of PRK in low-moderate myopia $(2,3,10,17,18)$. Moon et al. reported that the refractive stability is not influenced by high-altitude environmental stress and that stabilization of the refraction accrues in a duration of 6 months. In this study, 38 eyes of 20 patients were evaluated after PRK. Spherical equivalent was $-1.51 \pm 1.15$ diopters before the study and $-0.29 \pm 0.51$ diopters at 4 years after the study. Snellen uncorrected visual acuity was $20 / 20$ or better in $89.5 \%$ of the eyes after surgery (2). Alio et al. reported safety of PRK in 3000 eyes. In this study, a decrease in best corrected visual acuity was reported in $10(0.7 \%)$ eyes 1 year after surgery (7). Myopia ranged from -1.0 to -14.0 diopters in this study. Also the range for astigmatism was -1.0 to -5.0 diopters. Severe haze was reported in 17 eyes in the first year after surgery. The rates for progressive hyperopia, eccentric ablation, delayed re-epithelialization, and recurrent corneal erosion was very low. One study reported on the safety of PRK in 18 years' follow-up (8). This study reported no evidence for ectasia after 18 years' follow-up in 46 patients. However, a significant increase in myopic spherical equivalent was reported in patients older than 40 years and in females during follow-up. Also Shalchi et al. demonstrated improvement in corrected distance visual acuity and corneal transparency in these patients (8). Mean spherical equivalent was -4.86 diopters before operation. Mean spherical equivalent change was -0.31 diopters between 1 and 18 years after study. This 
change was -0.54 diopters in patients younger than 40 years and -0.05 diopters in patients older than 40 years and 0.40 diopters in women and -0.08 diopters in men. The efficacy and safety index was reported to be 0.58 and 0.998 , respectively. In this study, the thinnest abnormality was decreased after surgery. This can be due to increased collagen synthesis after operation. Another cause may be due to variation in measurement by the device. We had no post-operation corneal ectasia or any other complications during the follow-up period in this study. Similar results were reported by Shalchi et al. in an 18 years' follow-up study. They also reported no case of ectasia in their study (8). Our findings are compatible with similar studies. Some studies on the efficacy and safety of PRK in keratoconus have reported a low risk for progression of keratoconus $(6,19)$. Atypical indices, including inferior steepening, high keratometery, low pachymetery, high anterior and posterior elevation and high SRAX had no influence on the rate of keratoconus in this study. Similar to the results of our study, Tambe et al. reported low risk for progression of keratoconus after PRK (6). In this study, 28 eyes were studied. Among them, five eyes had corneal transplantation, and four eyes were not available for follow-up. Among the remaining 19 eyes, corrected distance visual acuity was improved in $16(84.3 \%)$, declined in two (10.5\%), and unchanged in one (5.2\%) eyes. Also Khakshoor et al. reported similar results in patients older than 40 years with grade I or II keratoconus (19). In the mentioned study, variables such as keratometric readings, uncorrected visual acuity, best corrected visual acuity, spherical equivalent, and cylindrical power were evaluated. Based on our findings and findings of similar studies, the rate of keratoconus after PRK is very low; further, PRK is not associated with risk of progression of keratoconus. Although in our study all patients had asymmetric inferior steepening, no patient had keratoconus after operation. The increase in SRAX after operation may be due to the ablation procedure. Also factors such as keratometery and anterior elevation are not reliable after surgery. In this study, we have evaluated patients 1 to 7 years after surgery. One study on 18 -year follow-up of the patients after PRK have reported the stability of keratometery between 1 and 18 years after surgery (1). Some researchers also reported the stability of outcome even during the first year after surgery (20). However, some researchers have reported the decrease in efficacy of PRK within years $(3,8)$. In summary, our study and studies by other researchers show high stability in the result of keratometery. Therefore, it seems that PRK has good efficacy and safety in patients with atypical topography.

\section{Conclusions}

Although atypical topography, including inferior steepening with an asymmetrical bow-tie, may have potential risk of post-PRK ectasia, this study revealed that, if other topographic and tomographic data are within the normal limit, PRK can be a safe procedure. In eyes with inferior steepening as a sign of atypical topography, photorefractive keratectomy has effective and safe outcomes with no post-operative complications. Therefore, we suggest PRK in eyes with inferior steepening.

\section{Acknowledgments:}

The paper is extracted from the results of a thesis by Dr. Ehsan Namvar for fulfilment of requirements required for acquiring the degree of specialty in ophthalmology. The authors want to thank the directors of Shiraz University of Medical Sciences for their help and support.

\section{Conflict of Interest:}

There is no conflict of interest to be declared.

\section{Authors' contributions:}

All authors contributed to this project and article equally. All authors read and approved the final manuscript.

\section{References:}

1) Wagh VK, Dave R, O'Brart DP, Lim WS, Patel P, Tam C, et al. Eighteen-year follow-up of hyperopic photorefractive keratectomy. J Cataract Refract Surg. 2016; 42(2): 258-66. doi: 10.1016/j.jcrs.2015.09.025. PMID: 27026451.

2) Moon CH. Four-year visual outcomes after photorefractive keratectomy in pilots with low-moderate myopia. Br J Ophthalmol. 2016; 100(2): 253-7. doi: 10.1136/bjophthalmol-2015-306967. PMID: 26135012.

3) Alio JL, Soria FA, Abbouda A, Pena-Garcia P. Fifteen years follow-up of photorefractive keratectomy up to $10 \mathrm{D}$ of myopia: outcomes and analysis of the refractive regression. Br J Ophthalmol. 2016; 100(5): 62632. doi: 10.1136/bjophthalmol-2014-306459. PMID: 26359339. 
4) Torres Neto E, Silva LM, Lui GA, Gomes RL, Lui-Netto A. Analysis of corneal esthesia in patients undergoing photorefractive keratectomy. Arq Bras Oftalmol. 2015; 78(6): 363-6. doi: 10.5935/00042749.20150096. PMID: 26677039.

5) Tomas-Juan J, Murueta-Goyena Larranaga A, Hanneken L. Corneal Regeneration After Photorefractive Keratectomy: A Review. J Optom. 2015; 8(3): 149-69. doi: 10.1016/j.optom.2014.09.001. PMID: 25444646, PMCID: PMC4502084.

6) Tambe DS, Ivarsen A, Hjortdal J. Photorefractive Keratectomy in Keratoconus. Case Rep Ophthalmol. 2015; 6(2): 260-8. doi: 10.1159/000431306. PMID: 26327912, PMCID: PMC4553919.

7) Alio JL, Artola A, Claramonte PJ, Ayala MJ, Sanchez SP. Complications of photorefractive keratectomy for myopia: two year follow-up of 3000 cases. J Cataract Refract Surg. 1998; 24(5): 619-26. doi: 10.1016/S0886-3350(98)80256-3. PMID: 9610444.

8) Shalchi Z, O'Brart DP, McDonald RJ, Patel P, Archer TJ, Marshall J. Eighteen-year follow-up of excimer laser photorefractive keratectomy. J Cataract Refract Surg. 2015; 41(1): 23-32. doi: 10.1016/j.jcrs.2014.05.034. PMID: 25467133.

9) Mohammadi SF, Nabovati P, Mirzajani A, Ashrafi E, Vakilian B. Risk factors of regression and undercorrection in photorefractive keratectomy: a case-control study. Int J Ophthalmol. 2015; 8(5): 933-7. 10.3980/j.issn.2222-3959.2015.05.14. PMID: 26558204, PMCID: PMC4630999.

10) Hashemi H, Miraftab M, Asgari S. Photorefractive keratectomy results in myopic patients with thin cornea eyes. Oman J Ophthalmol. 2015; 8(1): 24-7. doi: 10.4103/0974-620X.149860. PMID: 25709270, PMCID: PMC4333538.

11) Loewenstein A, Lipshitz I, Varssano D, Lazar M. Complications of excimer laser photorefractive keratectomy for myopia. J Cataract Refract Surg. 1997; 23(8): 1174-6. PMID: 9368160.

12) Edmison DR. Complications of photorefractive keratectomy. Int Ophthalmol Clin. 1997; 37(1): 83-94. PMID: 9101347.

13) Randleman JB, Woodward M, Lynn MJ, Stulting RD. Risk assessment for ectasia after corneal refractive surgery. Ophthalmology. 2008; 115(1): 37-50. doi: 10.1016/j.ophtha.2007.03.073. PMID: 17624434.

14) Randleman JB, Trattler WB, Stulting RD. Validation of the Ectasia Risk Score System for preoperative laser in situ keratomileusis screening. Am J Ophthalmol. 2008; 145(5): 813-8. doi: 10.1016/j.ajo.2007.12.033. PMID: 18328998, PMCID: PMC3748728.

15) Binder PS. Risk factors for ectasia after LASIK. J Cataract Refract Surg. 2008; 34(12): 2010-1. doi: 10.1016/j.jcrs.2008.08.035. PMID: 19027544.

16) Colin J, Cochener B, Bobo C, Malet F, Gallinaro C, Le Floch G. Myopic photorefractive keratectomy in eyes with atypical inferior corneal steepening. J Cataract Refract Surg. 1996; 22(10): 1423-6. PMID: 9051496.

17) Hashemi M, Amiri MA, Tabatabaee M, Ayatollahi A. The results of photorefractive keratectomy with Mitomycin-C in myopia correction after 5 years. Pak J Med Sci. 2016; 32(1): $225-8$. 10.12669/pjms.321.8576. PMID: 27022380, PMCID: PMC4795874.

18) See B, Tan M, Chia SE, Gan WH, Low R, Nah G. Photorefractive keratectomy in young Asian aviators with low-moderate myopia. Aviat Space Environ Med. 2014; 85(1): 25-9. PMID: 24479255.

19) Khakshoor H, Razavi F, Eslampour A, Omdtabrizi A. Photorefractive keratectomy in mild to moderate keratoconus: outcomes in over 40-year-old patients. Indian J Ophthalmol. 2015; 63(2): 157-61. doi: 10.4103/0301-4738.154400. PMID: 25827548, PMCID: PMC4399126.

20) Sakla H, Altroudi W, Munoz G, Sakla Y. Simultaneous Topography-Guided Photorefractive Keratectomy and Accelerated Corneal Collagen Cross-Linking for Keratoconus. Cornea. 2016; 35(7): 941-5. doi: 10.1097/ICO.0000000000000843. PMID: 27124776. 